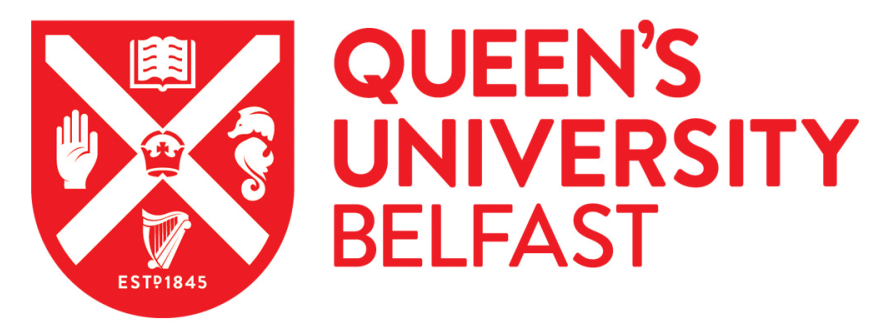

\title{
Between Tradition and Modernity: Determining Spatial Systems of Privacy in the Domestic Architecture of Contemporary Iraq
}

Al-Thahab, A., Mushatat, S., \& Abdelmonem, M. G. (2014). Between Tradition and Modernity: Determining Spatial Systems of Privacy in the Domestic Architecture of Contemporary Iraq. ArchNet - IJAR, 8(3), 238-250. http://www.archnet-ijar.net/index.php/IJAR/article/view/396

Published in:

ArchNet - IJAR

Document Version:

Publisher's PDF, also known as Version of record

Queen's University Belfast - Research Portal:

Link to publication record in Queen's University Belfast Research Portal

Publisher rights

Copyright 2014 The authors

This is an open access article published under a Creative Commons Attribution-NonCommercial-NoDerivs License (https://creativecommons.org/licenses/by-nc-nd/4.0/), which permits distribution and reproduction for non-commercial purposes, provided the author and source are cited.

\section{General rights}

Copyright for the publications made accessible via the Queen's University Belfast Research Portal is retained by the author(s) and / or other copyright owners and it is a condition of accessing these publications that users recognise and abide by the legal requirements associated with these rights.

Take down policy

The Research Portal is Queen's institutional repository that provides access to Queen's research output. Every effort has been made to ensure that content in the Research Portal does not infringe any person's rights, or applicable UK laws. If you discover content in the Research Portal that you believe breaches copyright or violates any law, please contact openaccess@qub.ac.uk. 


\title{
BETWEEN TRADITION AND MODERNITY: Determining Spatial Systems of Privacy in the Domestic Architecture of Contemporary Iraq
}

\author{
Ali Al-Thahab \\ School of Architecture and the Built Environment, \\ University of Wolverhampton \\ ali.althahab@yahoo.co.uk \\ Sabah Mushatat \\ Professor, School of Architecture and the Built Environment, \\ University of Wolverhampton \\ s.mushatat@wlv.ac.uk \\ Mohammed Gamal Abdelmonem \\ Lecturer, School of Planning, Architecture and Civil Engineering, \\ Queens' University Belfast \\ m.gamal@qub.ac.uk
}

\begin{abstract}
The notion of privacy represents a central criterion for both indoor and outdoor social spaces in most traditional Arab settlements. This paper investigates privacy and everyday life as determinants of the physical properties of the built and urban fabric and will study their impact on traditional settlements and architecture of the home in the contemporary Iraqi city. It illustrates the relationship between socio-cultural aspects of public/private realms using the notion of the social sphere as an investigative tool of the concept of social space in Iraqi houses and local communities (Mahalla). This paper reports that in spite of the impact of other factors in articulating built forms, privacy embodies the primary role under the effects of Islamic rules, principles and culture. The crucial problem is the underestimation of traditional inherited values through opening social spaces to the outside that giving unlimited accesses to the indoor social environment creating many problems with regard to privacy and communal social integration.
\end{abstract}

Keywords: Privacy; Traditional built environment; Social sphere; Urban sphere; Public/Private spaces.

\section{INTRODUCTION}

The concept of privacy represents an important factor in the articulation of the built environment which has been largely interrogated in the analysis of the architecture of home and spatial organisation of social spaces (Abdelmonem, 2010). The moral and behavioural system of Islam; as in the revelations of the holy Qur'an (4, 5 - 49), "Indeed, those who call you, [O Muhammad], from behind the chambers - most of them do not use reason, And if they had been patient until you [could] come out to them, it would have been better for them. But Allah is Forgiving and Merciful;" prescribe a central criterion in determining privacy in the shaping of domestic social life of Iraqi society, yet they can equally be observed in non-Muslim communities in Iraq. Privacy, hence, helps to refine the interrelationship between spaces within the same living unit or between the unit and the outside context (Stewart, 2001). The separation of public/private spaces summarizes the impact of the cultural and behavioural value systems on the sequence and hierarchy of spaces that largely defines the organic pattern of the traditional fabric at large. This context, in turn, introduces harmonious, integrated and controlled social relations within. Most cases dealing with privacy end up in separating the public from the private through physical, 
behavioural and spatial codes which relate them to a consistent set of rules within a specific society (Abu-Gazzeh, 1993). The traditional house obtains its priority over public realms as it accommodates the social and cultural aspects of life. It demonstrates, moreover, the thresholds of social interaction between male and female members of the same family in the everyday social practices (Alizadeh, 2005). This is reflected in the architecture of the house through dividing it into two distinct parts: male section 'Diwan-khana', and female part 'Haram' (Fethi, 1977).

Intrinsic to modernity is the underestimation of inherited socio-cultural values that have limited the impact of privacy and opening social spaces to the outside, giving unlimited visual accesses to indoor social contexts and creating many restrictions with regard to privacy and communal social integration. Modern architects and planners tend to neglect the centrality of privacy in the housing design process with some considering it a limitation to freedom of design. Moreover, formal aesthetics, economic factors and new technological methods are among those deemed more important in the progress of design mechanism than inherited social and cultural values (Eben Saleh, 1997).

This paper aims at addressing the changing characteristics and re-evaluates the architecture of home according to the concept of privacy. It attempts to answer a central question; 'how does the change of our attitude to privacy affect the latent aspects of house design and planning in contemporary Iraq?' For achieving a built environment that is more responsive to the needs and requirements of its users in terms of privacy and social interaction, one should analyse both traditional and contemporary settlements in Iraq. The first will give an idea of the meaning of privacy and its interpretations as well as the dynamic of public and private social spaces in traditional and contemporary built environment. It will address the importance of privacy and social flexibility or fluidity in the spatial organisation of Iraqi traditional home and residential quarter - mahalla. The following part will study the impact of modernity in changing the latent socio-cultural aspects of society and respectively the articulation of the home and the spatial morphology of the neighbourhood unit. Finally, conclusions including key design implications of how socio-spatial aspects of privacy can be considered in future Iraqi development efforts will be produced.

\section{METHODOLOGY}

On the basis of the nature of research's question and inquiry, this study is of qualitative nature that is effective in identifying the intangible factors of the human side and in understanding the practice of everyday life. In-depth, open-ended and unstructured interviews with users from both contexts, the traditional and the contemporary, were mainly used to obtain the relevant information. This method offers the opportunity of observing the real meaning of the idea in question. Moreover, it helps to observe how consciously users relate privacy to their home environment and the surrounding. Many educated and working-class users of both contexts refer to the same rule, as the majority of traditional context's households, or, preferably, middle class have been interviewed. This segment of society is more rational, spontaneous in their relationships and social behaviour and open in their discussions and judgements.

This paper depends on theoretical investigation, spatial analysis and analytical discussions with architects, planners and general public who are engaged with these environments frequently. Case studies of both contexts have been analysed spatially to find out the role of the socio-cultural aspects of privacy in determining the spatial characteristics of the specific home environment.

\section{ON PRIVACY AND THE HOME}

The notion of privacy acquires various interpretations in different contexts. A clear definition of privacy is needed to accommodate the different social and cultural changes. Basically, privacy is defined as the mechanism of developing and maintaining process in the mutual relationship among individuals, within a small social group or in society at large. Irwin Altman (1975) indicated that, individual's identity and personality can be achieved and maintained by the guidance of 
privacy through the creation of fundamental personal boundaries (Al-Homoud, 2009). Alan. F. Westin (1967) argued that, privacy works as the withdrawal of individual from society through the use of physical and behavioural boundaries. Individual's need to be included in the social intercourse of everyday life is a considerable determinant in the perception of the social space and boundaries of privacy. In this respect, privacy is never absolute as long as it refers to a changeable social and cultural sphere and interaction (Ramezani \& Hamidi, 2010).

According to Altman (1975), privacy represents the interpersonal boundary-control process which organizes our social interactions in manners similar to the shifting permeability of a cell membrane. Moreover, it is a dialectic mechanism and a system that stands between the restriction of interpersonal boundaries and being part of society through its dynamic ability of pushing towards an essential degree of openness-closeness, or accessibility-inaccessibility. This mechanism occurs with the presence of the relative reaction of various powers which change temporarily according to different circumstances. Altman presented the 'desired' and 'achieved' privacy where the subjectivity of the first is in the nobility of the sociocultural interactions between people at a specific period of time (Georgiou, 2006). For Rapoport (1977), privacy is the power and ability of managing social and cultural interactions between different social groups and being responsible for achieving the desired and acquired level of interaction (Ramezani \& Hamidi, 2010). Seeking a degree of privacy does not mean, according to Schwartz (1986), the desire for achieving social isolation but a communicative mechanism and guide for human social behaviour and showing at the same time the socio-physical boundary which isolate two different spaces (Georgiou, 2006). In this sense, privacy ought to be conceptualized according to its relation with the different meanings of private and public realms.

\section{THE CONCEPT OF PUBLIC/PRIVATE REALMS}

Public and private domains have an essential role in the articulation of spaces. The social, cultural or physical division of urban spaces into public and private realms expresses the relation between the two different spheres in society which reflect respectively the different types of relations that combine the individual with society and, in other words, between the self and the others within the same context.

Public spaces have basically been related to spaces where social interactions can take place in larger groups without censorship. They show the embodiment of the notion of promotion into the unrestricted visibility or accessibility of social interactions such as being in a street coffeehouse or in a shopping centre. However, the socio-cultural notion of the private/public segregation refers to the meaning of the private realm and its different spaces. The female domain provides a high degree of desired privacy, secrecy, concealments and isolation from the attention of the public. This mechanism articulates the integral meaning of privacy including visual, aural and accessibility determinants (Rahim \& Abu Hassan, 2011). The intimate, closed and separated private domain and the opposite public one constitute a social and contextual environment of people's daily life in an interrelated relationship. They present the realisation of relatedness and being with each other in every single action. This idea can be clearly shown when, for example, the public domain of the alleyway 'agd' in local communities transforms into private to accommodate diverse social and cultural occasions (Abdelmonem, 2011).

The role of public/private domains can simply be understood by referring them to a specific system of social spaces for the purpose of presenting their indications. This kind of classification has different forms and layouts. The private realm articulates the innermost part of conscious in human beings and shows the most secure and safe environment through viewing some kind of refuge fields from the public. Consequently, the public realm appears to be in accessible attribute to all other social spaces, except the innermost part of the human (Abdelmonem, 2012a; Mazumdar and Mazumdar, 2001).

The term 'sphere' has been used by different studies concerning people's social interaction and intercourse (Abdelmonem, 2011). In the case of environmental psychology, each person is realized and perceived through an invisible shelter or a series of shelters surrounding his body. 


\section{ArchNet $\lrcorner \dot{2}$ A}

International Journal of Architectural Research

These shelters are different among people and cultures. Time is central to the variety of these spheres due to the continuity of the reconstructed dynamicity of the environment (Hall, 1969). Habermas (1991) argued that each environmental context reflects one of these realms where the family stands in charge of the private. According to Sennett (1974); De Certeau (1984) and Tonkiss (2005), people, in traditional public contexts, act collectively establishing a sense of familiarity and reflecting the internal private domain. The crucial necessity of the private within the public realm has an important influence on the perception of the social sphere.

\section{SOCIAL PRIVACY IN IRAQI TRADITIONAL HOME ENVIRONMENT}

The home is a reliable organisation that can be more responsive to the changing needs of the family which thus can develop flexible solutions to the increasingly limited spaces to encompass the different needs. The perspective of different spaces of the house has been wrapped by various cultural, social and behavioural rules. Social habits, cultural values and lifestyle dictate the form of social spaces (Fig.1) (Khattab, 2005). Users of traditional context indicate that the spatial settings of the house can be rearranged formally and functionally according to the degree of privacy. Therefore, there is always an opportunity for informality with functions despite the rigidity of the house plan. (Boudiaf, 2010). This can, for instance, be shown clearly in the case of marriage and when the house is expecting the arrival of a new member through birth or marriage and the need for crucial changes in the spatial organization of the house to embrace the new family.
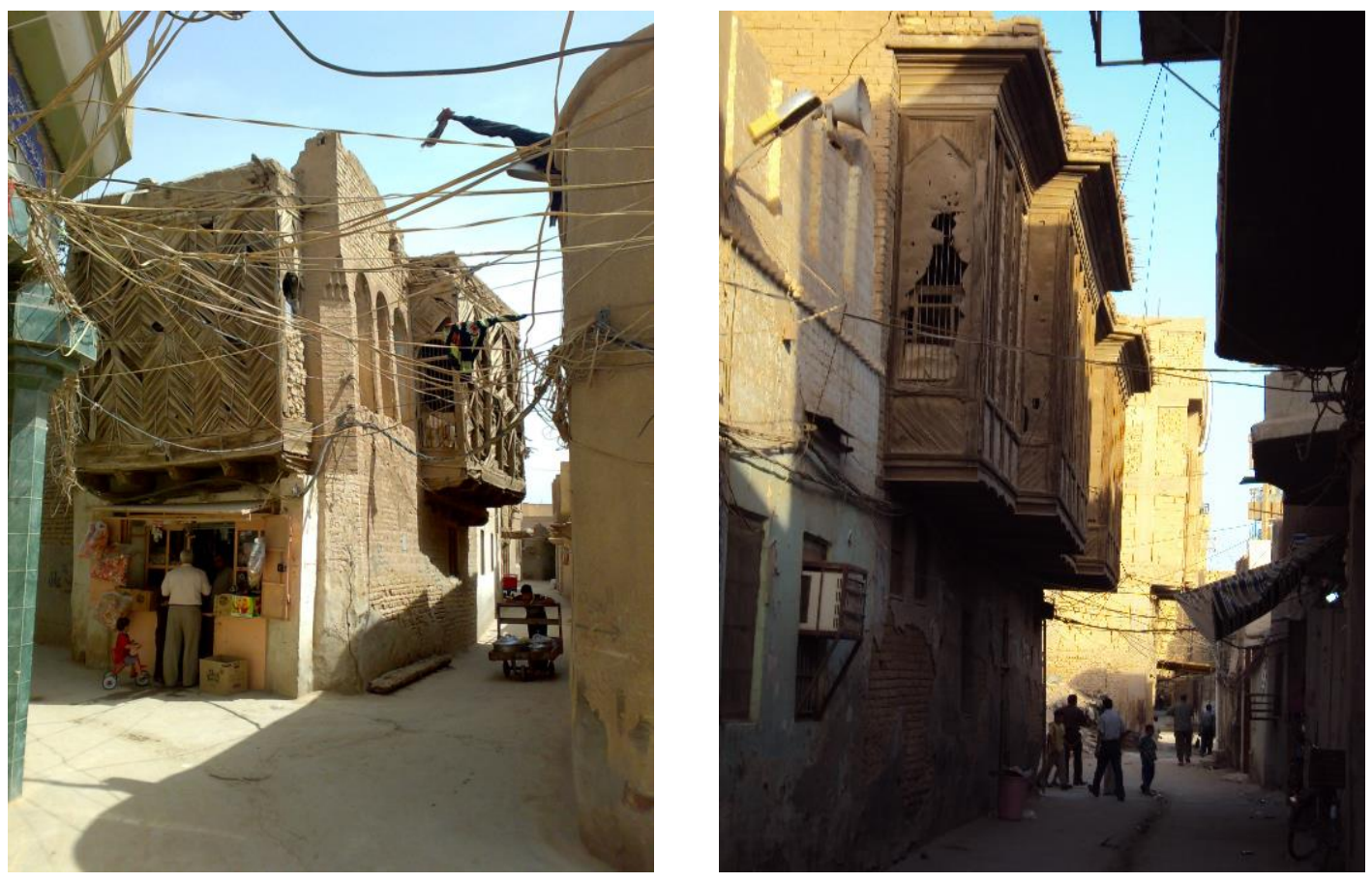

Figure 1: The compact built form and cohesive housing settlements in the old city of AlHilla-Iraq (Source: Authors).

Being alone is an indication of non-social involvement and building an exclusive environment within the house. Salama in 2006 argued that the determining factors in the formation of the traditional house are both the implicit and explicit socio-cultural and socio-religious beliefs and rituals which define what is really acceptable socially and what is not. In his discussion of the issues needed to provide affordable housing, Salama stated that environmental and sociocultural contexts demand should not aim at merely providing affordable shelters. It should also offer design solutions that are sensitive to the local contexts such as privacy, social cohesion, 
and perceptions on residential density, preferences, and the lifestyle of the target populations (Hashim and Rahim, 2008, p.95). The architecture of the traditional house and the spatial organization of its activities have the aim of holding family gatherings within a single protective shelter without intrusion from strangers (Hall, 1969, p.158). Physical and spatial treatments with regard to privacy, gender segregation and direct visual contacts have been performed in a manner that shows a deep understanding of social, cultural and religious values. This can be shown in the spatial and functional properties of the 'Iwan', 'Talar', the fountain 'shithirwan' which divides the court spatially, the plants and the variation in spaces' levels (Fig. 2).

The real concept of privacy in traditional domestic units in Iraq can be practised in the cantilevered elements (shanashil), the (ursi) and the (kabishkan) which represent physical components within the whole structural compound that help assert the privacy of its users (Fig.1, 3) (Warren \& Fethi, 1982). They are particularly important for women to ensure the notion of gender segregation and achieve a visual contact to the public outside or visitors inside the house without being observed except from those who belong to the same family. At the same time, the components of 'shanashil allow an interpersonal relationship between women of nearby houses to contact freely each other.

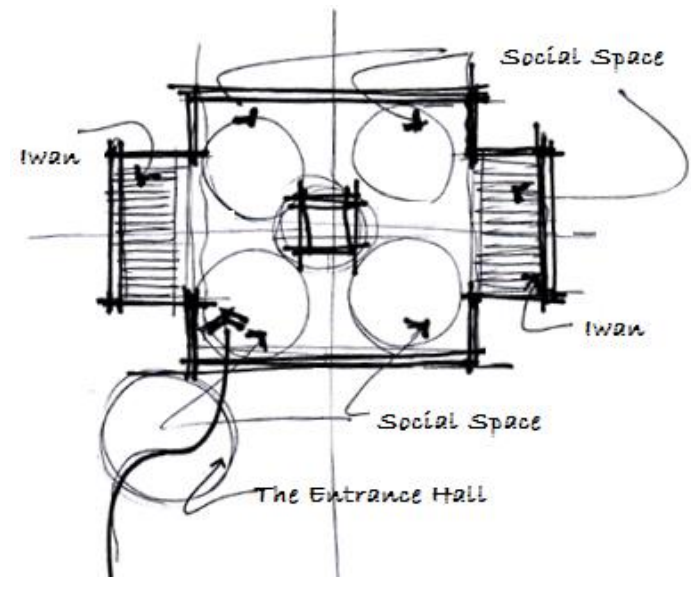

Figure 2: Social space \& privacy in traditional house

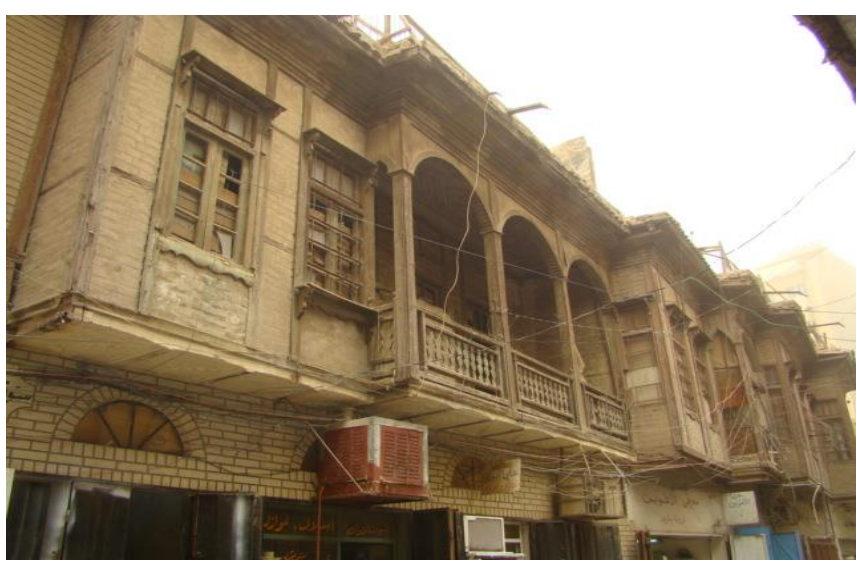

Figure 3: The courtyard house, Dar Babil in Al-Hilla-Iraq

Each house shows the private domain in various levels with regard to the nature of privacy, social groups and mechanisms used. Whilst the private refers in some degree to the concept of the public, the form of this relation and the different transitional spaces has the tendency to vary more over the course of time (Rapoport, 2007). The house has a range of public and private realms reflecting different activities over the course of time. It contains many physical boundaries which perform the thresholds between the public domain associated with the outside alleyway (agd); and the semi-public realm of the house illustrated by the entrance (mejaz) as shown in Al-Kubai house in Al-Kadhimiya-Iraq (Fig. 4) (Bianca, 2000; Fethi, 1977).

The space of the entrance has been articulated in a way that prevents any kind of direct visual intrusion from the outside towards the main social core of the house associated with the courtyard or the family room. Semi-private and, often, private realms represent particularly the socio-cultural core of the house, while the semi-public realm, which is in direct association with the semi-public realm of the entrance, views the world of men, guests and uninvited visitors as well as many public affairs such as wedding ceremonies. The public and private relations inside the house are largely arranged in relation to the lines of familiar strangers, guests and, most certainly, male-female relations (Madanipour, 2003; Bianca, 2000). The entrance hall encompasses an explicit spatial order and use. It regulates the personal properties of the place. That can also be shown in many contemporary designs as in the case of Rasool Hasoon's house in Kerbala-Iraq, designed by the architect Ali Al-Thahab, 2012 (Fig. 5). 


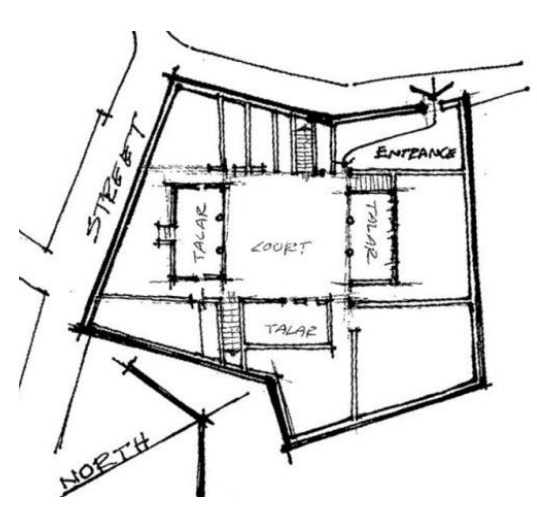

Figure 4: Al-Kubai house in Al-Kadhimiya, 1870, shows the spatial organisation and the position of the entrance with regard to the main social core (After Fethi, 1977)

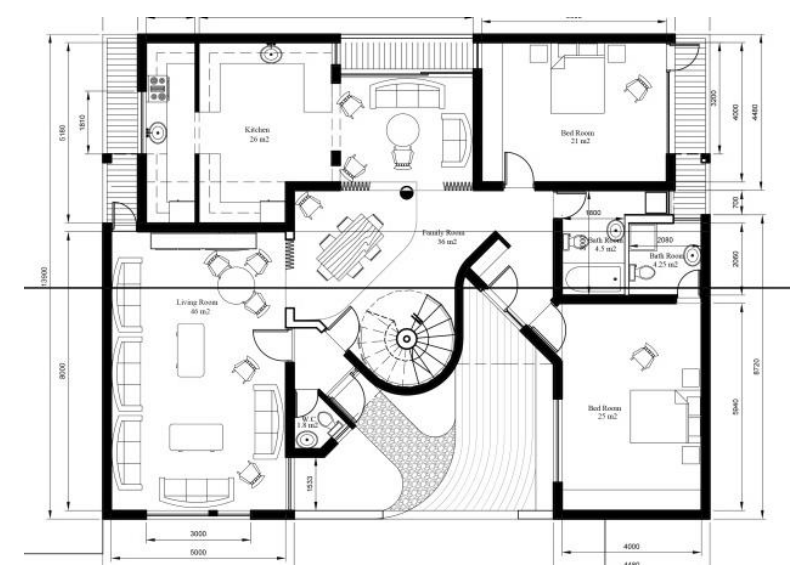

Figure 5: Rasool Hasoon's house in Kerbala Iraq, 2012 (Source: Authors).

\section{ASPECTS OF FLEXIBILITY IN IRAQI TRADITIONAL QUARTER: MAHALLA}

The spatial morphology of the traditional neighbourhood unit 'mahalla' depends on social activities and interactions very specific to its context within a certain period of time. There is always a flexible mechanism that emphasises the dynamic notion of the space socially. This includes various socio-cultural situations whose limitations can be changed continuously. Both domains in daily activities are flexible and not fixed to the impact of the physical boundaries of the house or sometimes the close outside world. In this sense, the private and public realms might be in an interchangeable social role temporarily. The public open space of the alleyway, 'agd', can be turned over into private during certain periods in spite of its public or semi-public nature. The social transitional nature of the alleyway has been used by female correspondingly as one of the internal spaces of the house. On such occasions, women from nearby units can gather in a small social group practicing their own social interactions and activities where men are outside the mahalla in coffee houses. Moreover, strangers, using the main public zone of the Mahalla, become a source of suspicion to be observed and exposed to a set of questions from the Mahalla's members and children who usually gather around asking many investigative questions such as: 'where are you going?' and 'which house are you looking for?' and so on (Rapoport, 2007; Abdelmonem, 2011).

Male visitors create another important daily occasion that affects the nature of the social space. On these occasions, the ground floor is socially turned over into public space while women use the first floor (Ragette, 2003). The social sphere of such spaces is flexible and can change into a public one when required. This mechanism strengthens social accessibility and permeability of certain spaces at specific times. Jurgen Habermas (1991) insisted that this mechanism represents the effective situation of both domains which has a great influence on the division of the social sphere and the nature of social spaces. The main family space, according to Rapoport (2007), shows a certain system of activities within the whole system of the house that could be indoor or outdoor. Consequently, the semi-public nature of reception areas, and many other social spaces, may be used as sleeping areas in specific periods by the rearrangement of fixed, semi-fixed or non-fixed features within the same space. Social and cultural flexibility can be practised in most private/public realms of the house and extended outside it demonstrating social, cultural and spatial continuity with the external public alleyway 'agd' (Abdelmonem, 2012b). Its predominant role is in strengthening the social relations and enhancing the level of social cohesion between society's members. This fluidity can be seen through many social practices such as wedding festivals or sorrow ceremonies where members of the Mahalla share and 
collaborate for the sake of the collective wellbeing and social solidarity using voluntary contribution through, for example, the performance of specific activities. Very frequently, they allow their houses to be at the disposal of their neighbour.

Culture and its different factors play a main role in influencing our behaviour and social interactions with others, whereas architecture is just a physical expression of that influence. People and their social, cultural and psychological aspects draw and define the physical properties of the home which in turn give a clear expression of the social style and status of the group using it. The degree of social and cultural consistency between the male/female, public/private, outside/inside and exterior/interior notions determines the architecture of the home within the cultural context of Iraqi society.

\section{MODERNITY AND THE CHANGING CULTURE OF IRAQ'S HOME ENVIRONMENT}

Since the early twentieth century and precisely following the oil-economy boom in Iraq in the 1970s, economic and political changes have affected the socio-cultural inherited aspects, traditions and, as a consequence, the behavioural patterns within the home. Due to the continuous migration of the population from rural areas to urban contexts and the large demand for new residential settlements which consequently sprang up in most Iraqi cities, new values and principles controlled by economic and political powers have emerged as the main determinants of the home and affected respectively the latent aspects of society (Raouf, 1985; Eben Saleh, 1997). The structure and the nature of the family have changed as the family unit becomes smaller or reduces in size. Male-residents tend to spend longer time with their families, thus, reducing their social interaction with some colleagues outside the boundaries of the neighbourhood unit. The elimination of transitional social spaces has forced them to limit their social relations to some formal visits that frequently take place within the physical properties of the house (Al-Wardi, 1965). Equally, rapid changes have affected architectural and planning standards following the universal practices of the international style and its association with industrial. Despite the recent concerns for health, safety and welfare, ideological preconceptions have ignored cultural values and, thus, provided a fundamental base for utopian concepts. The vital needs of the human have been neglected at the expense of physical and environmental factors which have been dominated by the concept of rationality, anonymity and increasing abstractions of social relations. The new approach marginalised the social features for the sake of the architectural image that is disconnected from local values and is largely implanted in irrelevant social context (Fig.6) (Heynen, 1999; Salama, 2006).

The concept of the public domain has changed to exclusively become squares and wide linear streets. The idea of the semi-private space and the everyday life concept have been rendered undesirable and set to be replaced with a rigid physical barrier between private and public. The provision of the in-between areas in traditional quarters met human needs, socially and culturally, in a more sensitive way than contemporary methods (Mousavi, 1998; Bianca, 2000; Ramezani \& Hamidi, 2010). As a natural result of modernity and its ideology, the concept of the neighbourhood as a home cannot effectively accommodate the coherent relations between former neighbouring families within the 'mahalla'. At the same time, the sensitive hierarchy of the different subdivisions of spaces, where the individual can locate his/her social; cultural and behavioural values into a clear system, are broken by the concept of the strict separation, represented by the rigid physical boundary of the outer wall, in contemporary designed residential quarters (Abdelmonem, 2011). The lack of social and cultural considerations represents the main weakness in the architecture of home (Hashim and Rahim, 2008). The new approach creates an extroverted form of houses, sometimes called villa pattern, situated in the centre of the individual lot. The private spaces are opened outwards creating unlimited accesses and lessen the sociocultural role of privacy. The notion of social space and/or social sphere in contemporary houses is distorted and unclear. It is misunderstood, ignored or actually underestimated as it represents an obstacle to modernity where the "Dwelling is now impossible... The house is past," (Theodor Adorno, cited in Heynen, 1999, p.17) (Fig. 7). In the context of philosophy, modernity frees the 


\section{ArchNetr」它}

International Journal of Architectural Research

human from the limitations and impact imposed by his family, community and local habits (Heynen, 1999).

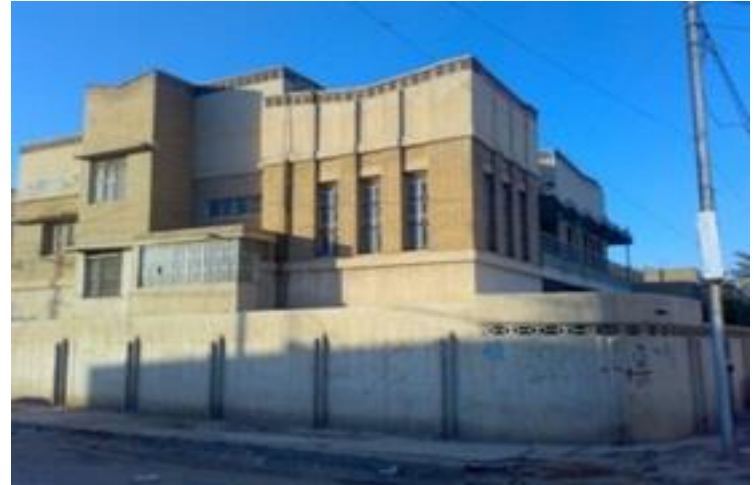

Figure 6: Raouf Shnawa's house of the 1960s-70s of the last century in the city of Al-Hilla, Iraq. The physical properties of the elevation demonstrate the notion of privacy (Source: Authors).

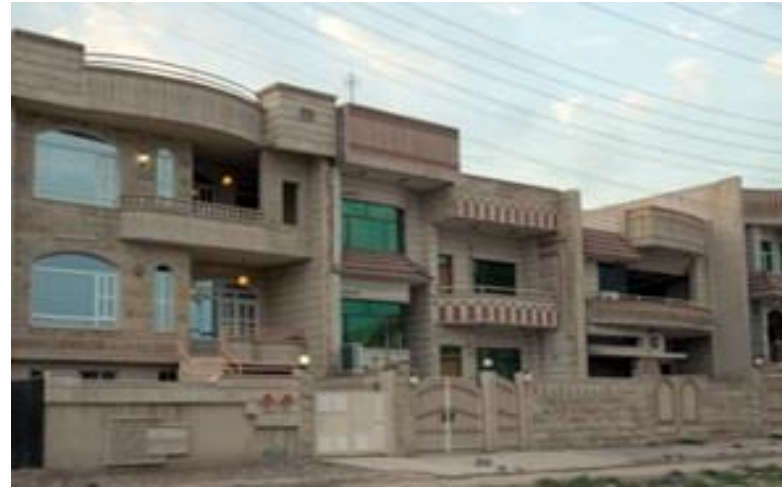

Figure 7: Contemporary residential units in Iraq and the openness towards the outside public realm (Source: Authors).

The concept of family social space as the main multifunctional activity space has been diminished through dividing the inside territory of the house into separate closed spaces indicating specific functions (i.e., bed rooms, kitchen, dining, etc.). Some architectural treatments have old and traditional effects such as the balcony on the first level which has been closed by lightweight screen materials to get an additional space and prevent visual intrusion from opposite or adjacent houses reflecting the concept of the 'shanashil'. This can also be recognized in the segmentation of the social space through the use of different levels which reflects the difference in levels between the courtyard (hosh) and the open reception space (iwan). In such treatments, families have tried to gain more separate spaces in order to satisfy their basic needs and achieve privacy or social segregation which modernity has failed to provide (Fig. 8) (Abu-Gazzeh, 1993).

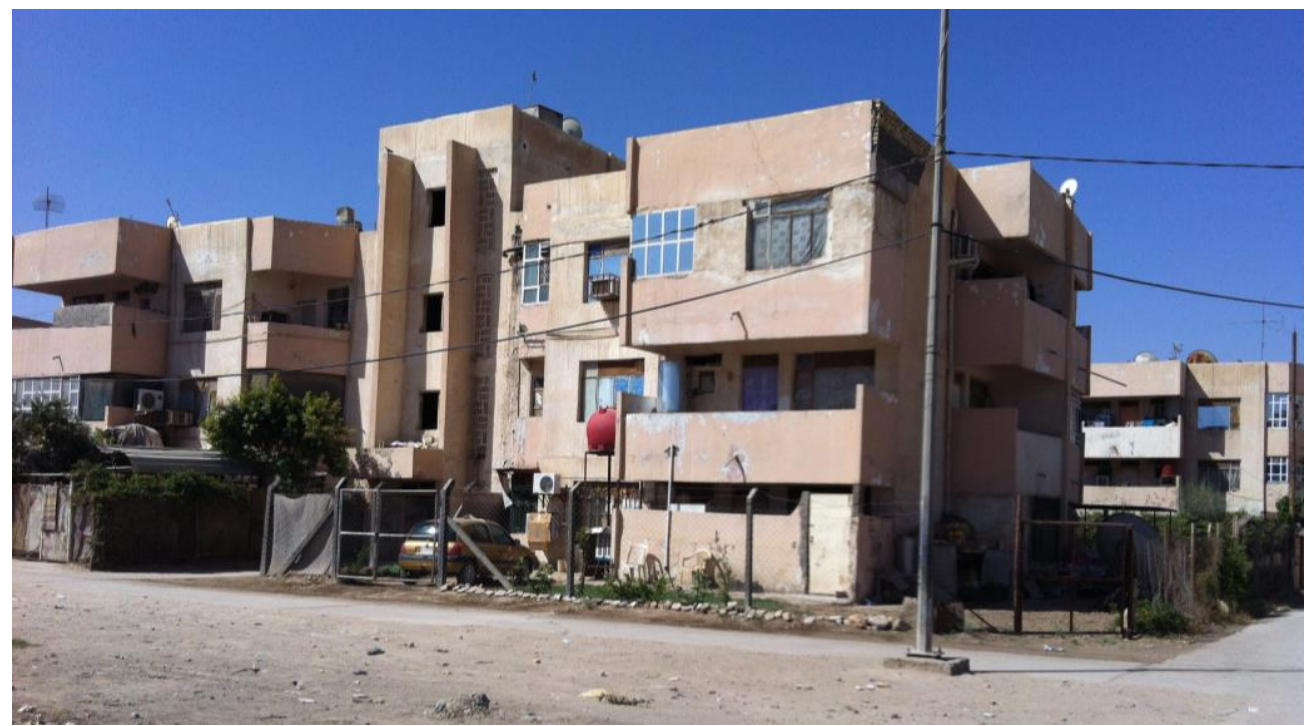

Figure 8: The impact of the new trend on privacy and the socio-cultural aspects of society (Source: Authors).

\section{MODERNITY AND PRIVACY IN IRAQ'S NEW QUARTERS}

The changes in the architectural factors and the planning principles of the small neighbourhood unit from organic and spontaneous form to geometric and grid-iron pattern affects largely the concept of private/public domains and the prominent impact of transitional social spaces. It also 
affects the humanity of the individual and his personality as long as it destroys his security and privacy. Accordingly, the neighbourhood unit has gained an extroverted form rather than the introverted concept of the traditional which presented the mahalla as an isolated and integrated complex socially, culturally, economically and politically. The new doctrine has led to the transition from the inner core of the mahalla to the outside providing easy and wide accesses for the penetration of the car and direct visual view from the outsider towards the inner social space of the house. Respectively, the social, cultural and structural properties of the newly designed residential quarters have been broken through the elimination of transitional realms which have a negative impact on residents' everyday life (Fig. 9).
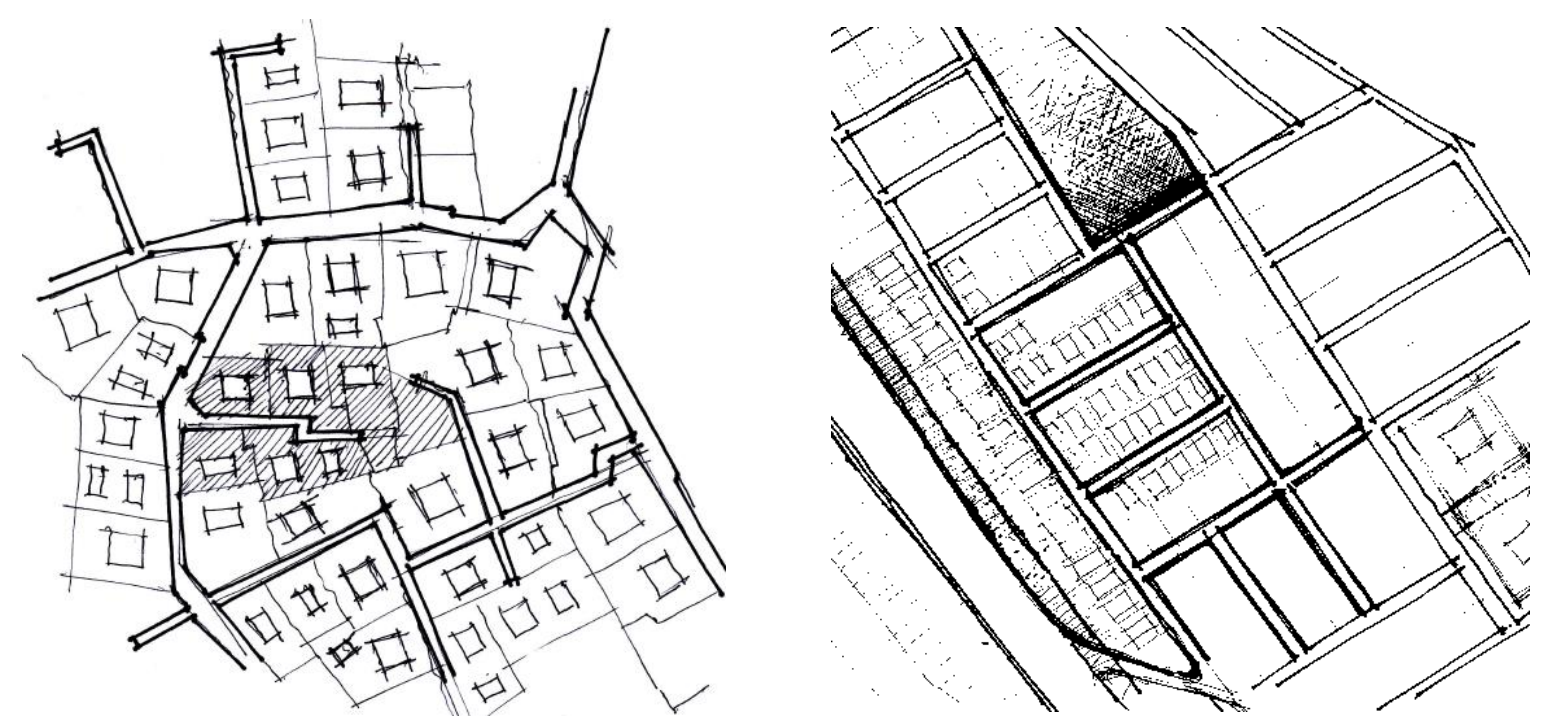

Figure 9: A typical residential neighbourhoods with the organic pattern (left) and the gridiron pattern (right) in AlKadhimiya- Baghdad (Source: Authors).

Modernity affects in most cases the everyday conditions of Iraqi society through the destruction of the informal networks of social bonds and mutual responsibilities replacing them by a highly formalised administrative system (Bianca, 2000). Modernity changes the concept of the 'single family', 'home' and 'dwelling' as well. These concepts, according to theorists of modernity, fade into the distance, while all assert that modernity and dwelling are completely opposed to each other (Heynen, 1999). Indeed, with regard to the neighbourhood unit, the social gathering space of the residents in traditional open spaces have been diminished and confined to certain areas in specific corners of the residential blocks. Moreover, social interactions and festivities have been moved to specific places outside the boundaries of the mahalla and sometimes with the absence of its people especially when there is a differentiation on the basis of wealth and poverty (Eben Saleh, 1997). As a result of these thoughts, a sense of privacy, security, belonging and communal affiliation have been marginalized and eliminated. This can be clearly seen through the breaking of woman's privacy by members of the same quarter in contrast to traditional customs and norms. As a reflection of this phenomenon, the family takes some physical actions against these abnormal behaviours in order to achieve privacy as in the construction of high solid walls or fences, changing the position of private spaces to the opposite side of the house, closing the front windows on first floors and many others.

The main intellectual dimensions of the new approach involve drawing strict boundaries between the public and the private for achieving privacy, restricting social gathering within the unit and the residential quarter, having less involvement in the public sphere......while the traditional involves blurred boundaries and ease of access from the private to the public and vice versa in a proper sequence (Abdelmonem, 2012b). People, in general, have the desire to interact socially and culturally with others in open contexts with the presence of tangible boundaries 
(Sennett, 1974; Abdelmonem, 2011). This concept presents the limiting barrier of social interactions through the establishment of strict guidelines and principles for managing people's interaction and behaviour (Abu-Gazzeh, 1993).

One of the main deficiencies of modernity was its contempt and disregard for the inherited social, cultural, spiritual and physical environments as proved in its refusal of historically grown built environments (Bianca, 2000). This concept was revealed through the rejection of the organic pattern of the traditional in favour of the benefits of the anti-social gridiron approach. The crucial point was that contemporary settlements have been imported as unquestioned developments and complete packages (Eben Saleh, 1997) as the case of most developments in Iraq after 2003 (Nagy, 2006) (Fig. 10). This type of change affects the social and cultural norms of Iraqi people and precisely privacy and social communications.

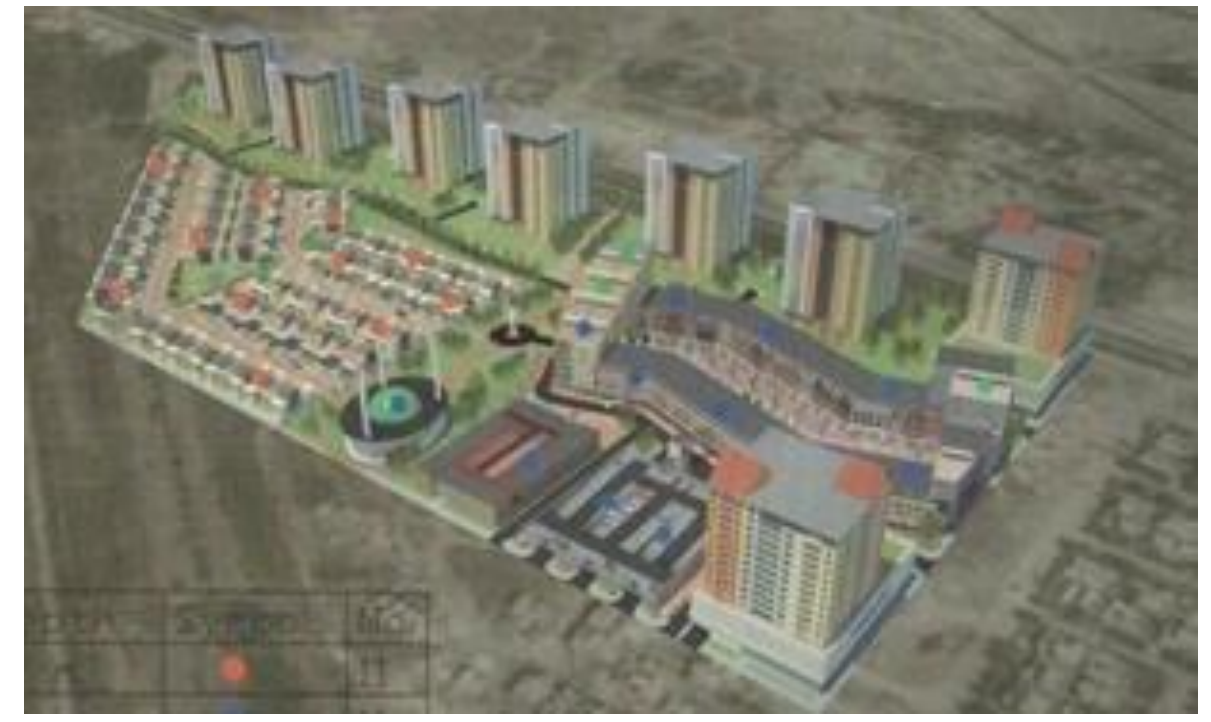

Figure10: A developing project which is under construction in the city of Al-Hilla- Iraq (Source: Authors).

\section{CONCLUSION}

The rapid and successive economic and political changes in Iraq in the last three decades, especially after 2003 and Iraq's entry into a new transitional stage of social, cultural, religious and intellectual transformative conflicts, have affected people's social and cultural values and the associated psychological and behavioural aspects to adhere to contemporary principles of the home environment. Following a long period of deprivation experienced by the Iraqi people, there has been a sudden openness towards modernity in its all impressive aspects. The differentiation in layers of Iraqi society has been influenced by the changeable categories of socio-cultural and religious factors. All these changes affect the architectural properties of the house as long as the physical and spatial arrangement of the house and the use of the social space are metaphors for the invisible image of the social and cultural values of society.

Privacy, as a social and cultural aspect, is a serious matter in the spatial formation and articulation of the built environment in Iraq. For communities, privacy plays an important factor in strengthening and accommodating communal social interactions which, in turn, strengthens the ability of space in achieving a more sustainable and secured residential environment. There is a crucial need to understand the concept of privacy and its related social, cultural and psychological issues in architectural practices and philosophies. In future development efforts for sustainable home environments in Iraq, the emphasis need to be on the importance and necessity of personal privacy in the socio-spatial organisation of the home rather than the personal space which represents the perspective of Western movement. Moreover, a 
comprehensive study of all segments of Iraqi society is crucial for understanding privacy and its role as a means of knowledge for the common good of the house.

The house, as the basic social and human organisation, encompasses many systems of activities which are different in their socio-cultural nature. These systems have been viewed as social spheres which present essential factors in expressing social spaces. This notion is embodied by dividing the space according to the social nature and the degree of privacy that can be obtained. Therefore, the significant concept of the social sphere is in the classification of spaces socially to the public/private and the transitional spaces to achieve the best arrangement for interior and exterior spaces.

The hierarchical and sensitive subdivision of social spaces on the scale of the Mahalla and the house is an effective mechanism in response to the changing requirements of the social group. It reflects the sustainable aspects of the social activities within the home through maintaining privacy and social interaction. The mechanism, used in achieving the transitional spatial sequence in traditional context, creates the essence of social, cultural and behavioural fluidity in everyday life and the reciprocal relation between the social space and the activity over the course of time. These aspects need to be re-evaluated in contemporary Iraqi settlements to provide an active mechanism for more sustainable developments.

It is important to investigate, analyse and study the neighbourhood unit according to the socio-cultural aspects of the human in order to create a relevant social context instead of the spatial demands of the car which represents the main determinant in contemporary one. A sense of privacy, security, belonging and communal affiliation are crucial factors in creating the concept of the neighbourhood as a home. This approach can be applied by associated and shared values between decision makers and an effective and active participation from local users.

In the meantime, creating responsive settlements that respond to the concern over privacy, building regulations, frameworks for architects and developers provide a better and engaging living environments that consider the application of the socio-spatial needs of its users a central strategy for successful planning and housing design.

\section{REFERENCES}

Abdelmonem, M. G. (2012a). The Practice of Home in Old Cairo: Towards Socio-Spatial Models of Sustainable Living. TDSR, Vol. 23, No.2, pp. 35-50.

Abdelmonem, M. G. (2012b). Responsive homes of old Cairo: Learning from the past, feeding in the future. Hospitality \&Society,Vol. 2, Issue 3, September 2012, pp. 251-271(21).

Abdelmonem, M. G. (2011). Understanding Everyday Homes of Urban Communities: The Case of Local Streets (Hawari) of Old Cairo. Journal of Civil Engineering and Architecture, ISSN 1934-7359, USA, Vol. 5, No.11, (Serial nr. 48): 996-1010.

Abdelmonem, M. G. (2010). The Architecture of Home: An investigation of the practice of home in the hawari of old Cairo 1800-2009, Ph.D. Thesis, University of Sheffield.

Abu-Gazzeh, T. (1993). Privacy as the Basis of Architectural Planning in the Islamic Culture of Saudi Arabia. Arch.\& Comport./ Arch. \& Behav., Vol. 11, No. 3-4: 269-288.

Al-Homoud, M. (2009). Privacy Control as a Function of Personal Space in Single-Family Homes in Jordan. Journal of Design and Built Environment, Vol. 5, December 2009, pp. 31-48

Altman, I. (1975), Environment and Social Behaviour. Monterey: Ca. Brooks/Cole, ISBN: 0818501685.

Al-Wardi, A. (1965). A study in the nature of Iraqi society - an introductory attempt to study the largest Arab community in the light of modern sociology. Arab House of encyclopaedias- Books Forum of literature, language, and thought, Baghdad-Iraq.

Bianca, S. (2000). Urban Form in the Arab World - Past and Present. London: Thames \& Hudson.

Boudiaf, B. (2010). Physical, Cultural and Cognitive interaction in the conception and the production of the Built Environment. Ph.D. Thesis, University of Wolverhampton.

De Certeau, M. (1984).The Practice of Everyday Life, Vol.1 (London: University of California Press, 1984).

Eben Saleh, M. A. (1997). Privacy and Communal Socialization: The Role of Space in the Security of Traditional and Contemporary Neighbourhoods in Saudi Arabia. HABITAT"INTL. Vol. 21, No 2:167-184. 
Fethi, I. (1977). Urban conservation in iraq: the case for protecting the cultural heritage of Iraq with special reference to Baghdad including a comprehensive inventory of its areas and buildings of historic or architectural interest, PhD, Thesis, Vol. 1, The University of Sheffield, UK.

Georgiou, Michael (2006), Architectural privacy a topological approach to relational design problems.Ms.C.Adaptive Architecture \& Computation, University College London.

Giddens, A. (1979). Central Problem in Social Theory: Action, Structure and Contradiction in Social Analysis. London: Macmillan.

Habermas, J. (1991). The Structural Transformation of the Public Sphere: An Inquiry Into a Category of Bourgeois Society. London: MIT Press.

Hakim, B. S. (1994). The 'URF' and its role in diversifying the architecture of traditional Islamic Cities. Journal of Architecture and Planning Research, Vol. 11, No. 2, pp. 108-127.

Hall, E.T. (1969). The hidden dimension, man's use of space in public and private. London, Sydney, Toronto: The bodley head.

Hauge, A. L. (2009). Housing and Identity The meaning of housing in communicating identity and its influence on self-perception. Ph.D. Thesis, NTNU Norwegian University of Science and Technology.

Hashim, A. H. \& Rahim, Z. A. (2008) The Influence of Privacy Regulation on Urban Malay families Living in Terrace Housing, Archnet-IJAR, Volume 2 - Issue 2 - July 2008- pp. 94-102.

Heynen, H. (1999). Architecture and Modernity: A Critique. MIT Press. Cambridge, Massachusetts; London, England.

Jiboye, A. D. \& Ogunshakin, L. (2010). The Place of The Family House in Contemporary Oyo Town, Nigeria. Journal of Sustainable Development, Vol. 3, No. 2, pp. 117-128.

Khattab, O. (2005). Socio-Spatial Analysis of Traditional Kuwaiti Houses,[online]. Proceeding: An abstract submitted for possible presentation at the IAPS, ENHR, \& KTH Conference, 2005, Stockholm, Sweden, pp. 1-18, [accessed 13 September 2013]. Available from: <http://www.infra.kth.se/bba/IAPS\%20papers\%20pdf/full\%20paper_030.pdf>.

Lawrence, R. (1987). Housing, Dwellings and Homes: Design Theory, Research and Practice. London: John Wiley \& Sons.

Lefebvre, H. (1997). The production of space. In Leach, N. (ed.), Rethinking Architecture. London and New York: Routledge, pp. 132-140.

Madanipour, A. (2003). Public and Private Spaces of the City. London and New York: Routledge.

Mazumdar, S. and Mazumdar, S. (2001). Rethinking Public and Private Space: Religion and women in Muslim society. Journal of Architectural and Planning Research, 18(4), pp. 302-324.

Mousavi, S. Y. (1998). Urban neighbourhoods of Tehran: the social relations of residents and their 'living place', Ph.D. Thesis, University of Newcastle Upon Tyne.

Nagy, G. (2006). Strengthening the Capacity of the Housing Sector in Iraq, UN-Habitat Iraq Programme, Housing Finance International, June 2006, pp. 3-8.

Ragette, F. (2003). Traditional Domestic Architecture of the Arab Region. Stuttgart-Felbach: Axel MengesGmbh.

Rahim, A. A. and Abu Hassan, F. Z. (2011). Study on Space Configuration and Its Effect on Privacy Provision in Traditional Malay and Iranian Courtyard House, IIUMPress, International Islamic University Malaysia, pp. 115-119.

Ramezani, S. \& Hamidi, S. (2010). Privacy and Social Interaction in Traditional Towns to Contemporary Urban Design in Iran. American Journal of Engineering and Applied Sciences, 3 (3): pp. 501-508.

Raouf, L. A. N. (1985). Sousing and Social Segregation in Iraq. International Journal of Urban and Regional Research, Vol. 9, Issue 3, September 1985.

Rapoport, A. (1977). Human Aspects of Urban Form. Oxford: Pergamon Press.

Rapoport, A. (1982). The Meaning of the Built Environment: A Nonverbal Communication Approach, Tucson, The University of Arizona Press.

Rapoport, A. (1990). The Meaning of the Built Environment: A Nonverbal Communication Approach, rev. ed. Tucson: University of Arizona Press.

Rapoport, A. (2007). The Nature of the Courtyard House: A Conceptual Analysis, (2007), TDSR, Vol. XVIII, No. II, pp. 57-72.

Sennett, R. (1977).The Fall of Public Man, London: Faber \& Faber Publishing.

Salama, A. M. (2003). The Courtyard House: Memory of Places Past. Dubai, UAE: Architecture +, Issue \# 3, pp.1-5.

Salama, A. M. (2006). A Typological Perspective: The Impact of Cultural Paradigmatic Shifts on the Evolution of Courtyard Houses in Cairo. Journal of the Faculty of Architecture, Middle East Technical 


\section{ArchNet}

University. Volume 23,

Issue 1, Faculty of Architecture, METU, Ankara, Turkey, PP. 41-58. ISSN \# 0258-5316.

Stewart, D. J. (2001). "Middle East Urban Studies: identity and meaning. Urban Geography 22(2), pp. 175181.

Tonkiss, F. (2005).Space, the city and social theory: Social relations and urban forms. London: Polity Press.

Warren, J., Fethi, I. (1982). Traditional Houses of Baghdad. Horsham, UK: Coach Publishing House Limited.

Westin A. F. (1967). Privacy and Freedom. New York: Atheneum.

\section{Authors}

Ali Al-Thahab

Ph.D. Researcher,

School of Architecture and the Built Environment, University of Wolverhampton

ali.althahab@yahoo.co.uk

\section{Prof. Sabah Mushatat}

Director of Studies,

School of Architecture and the Built Environment,

University of Wolverhampton

s.mushatat@wlv.ac.uk

\section{Dr. Mohammed Gamal Abdelmonem}

Lecturer in Architecture,

School of Planning, Architecture and Civil Engineering,

Queens' University Belfast

m.gamal@qub.ac.uk 